\title{
EFFECT OF ROSELLE BY-PRODUCT (Hibiscus sabdariffa L.) SUPPLEMENTATION ON THE PRODUCTION AND QUALITY OF JAPANESE QUAIL EGGS
}

\author{
PREVENA SINNIAH AND FAUZIAH TUFAIL AHMAD*
}

Faculty of Fisheries and Food Science, Universiti Malaysia Terengganu, 21030 Kuala Nerus, Terengganu, Malaysia.

*Corresponding author: fauziah.tufail@umt.edu.my

http://doi.org/10.46754/umtjur.2021.10.016

\begin{abstract}
Roselle (Hibiscus sabdariffa L.) is well-known for antioxidant properties and being utilised worldwide in the production of many processed products. Thus, the industrial production increases with the growing demand of roselle-based products. However, there is an alarming issue where the by-products or waste generated from the processing caused numerous risks for humans, animals and the environment. In this case, the utilization of bio-active compounds isolated from waste not only could reduce the risks and the costs for treatment of waste but also could potentially add more value for agricultural and food productions. Hence, this study aims to determine the effect of different concentrations of roselle by-product on physico-chemical content of Japanese quail eggs. Japanese quails were supplemented with roselle by-product to determine the effectiveness of the dietary treatments on the quality of the eggs. Parameters conducted included the number and weight of eggs, colour, pH, Haugh unit, ascorbic acid analysis and DPPH assay. There was no effect on the production viz total eggs and weight but significant differences were in other quality parameters such as albumen redness; albumen yellowness, $\mathrm{pH}$ and Haugh unit. Better performance of antioxidant properties can be obtained from treatment one with $2 \%$ of roselle by-product as compared to control and other treatments. In conclusion, the roselle by-product has tendency to provide nutritional attributes by antioxidant properties when it is incorporated into Japanese quail egg.
\end{abstract}

Keywords: Roselle, by-product, post-harvest quality, Japanese quail, egg, antioxidant.

\section{Introduction}

Roselle (Hibiscus sabdariffa L.) is an important cash crop that is largely grown in the East Coast of Malaysia especially in Terengganu and Kelantan (Wong et al., 2002). Being high in anthocyanin, roselle is both a good colorant and potentially a good source of antioxidants (Wong et al., 2002). Thus, it is processed into soft drink with daily consumption in many countries including Egypt, Sudan, Mexico, Nigeria and Thailand (Abou-Arab et al., 2011) which may contribute to the waste from their calyx.

Agri-industrial wastes are produced in large amounts and they require more landfill area to manage these wastes properly in order to prevent nuisance to the environment (Varzakas et al., 2016). The same circumstance goes to roselle by-product management as most of roselle byproducts are not able to be marketed. Since they can cause rapid spoilage and high costs of drying, storage and shipment, they tend to be disposed due to its high biodegradability (AyalaZavala et al., 2010). Statistically, it was stated by Ayala-Zavala et al. (2010) and Varzakas et al. (2016) that around $25 \%$ to $30 \%$ of inedible fruits and vegetable products were being discarded including roselle by-products. According to the finding by Baiano (2014), the large quantity of waste generated from agricultural and food production remains a great challenge and opportunity for the food industry to utilize the waste. This situation has led many researchers to conduct studies on agri-industrial waste management, that limit further exploitation.

The utilization of bio-active compounds isolated from waste not only could reduce the risks and the costs for treatment of waste but also could potentially add more value for agricultural and food productions (Robert et al., n.d.). Many 
researchers have found in their studies that those inedible parts of fruits and vegetables actually have higher nutrients than edible portions of fruits (Varzakas et al., 2016) and it can be said double in amount (Ayala-Zavala et al., 2010). Hence, in this study, roselle by-product is highly preferred to be used as the source of antioxidant supplement in manipulating Japanese quail's (Coturnix japonica) diet.

Since functional food like enriched-egg has to be produced from diet manipulation, it is more preferable to use agri-industrial waste like roselle by-product as mentioned earlier and easily done (Botelho et al., 2015). Moreover, addition of health-promoting additives from roselle by-product as animal feed can produce enriched-egg that has scientifically proven specific health benefit beyond their nutritional format (Mine, 1995). Few studies indicated that animal consumption of natural products not only can improve post-harvest quality of eggs but also protect the animals and their products against oxidation (Wenk, 2003; Descalzo and Sancho, 2008) feed intake and therefore optimize feed utilization. The health status of animals with a high growth performance is a predominant argument in the choice of feed additives. The use of feed additives is more and more questioned by the consumers. Therefore, the feed industry is highly interested in valuable alternatives which could be accepted by the consumers. Probiotics, prebiotics, enzymes and highly available minerals as well as herbs can be seen as alternatives. Herbs, spices and their extracts (botanicals. In addition, feed from agriindustrial waste is highly cost effective and minimizes any side effects from consumption of enriched-egg as they are made up of natural resources such as fruits and vegetable byproducts (Baiano, 2014). Till now, there are no research studies and solid facts on the effects of Japanese quail (Coturnix japonica) feed with roselle by-product on Japanese quail eggs. Thus, the objective of this study was to determine the effect of different concentrations of roselle by-product on the post-harvest quality of Japanese quail's egg. This study will provide useful information to the production sector of animal feed to formulate feed supplement by using plant by-products.

\section{Materials and Methods}

\section{Sample Collection and Materials}

The experiment was carried out at greenhouse as well as Postharvest Technology Laboratory, Universiti Malaysia Terengganu. A total of 36 units of Japanese quails and their commercial feed were purchased from local quail's farm at Kampung Pagar Besi, Terengganu. Fresh roselle was bought from a beverage processing industry in Terengganu.

\section{Samples Preparation}

Roselle by-products were produced from cordial processing as normally practiced by the local industry. A total of five $\mathrm{kg}$ of roselle were boiled with five $\mathrm{kg}$ of sugar and 7.5 litre of water for an hour. The cordial solution was filtered and the residue which was roselle by-products was cleaned and dried at $55^{\circ} \mathrm{C}$ for 24 hours. The dried roselle was ground into granules. The granules were kept at $-20^{\circ} \mathrm{C}$ for further use.

\section{Feeding Management}

A total of 36 Japanese quails were randomly allotted to four treatment groups with three replicates having three Japanese quail chicks each unit (Figure 1). Roselle by-product was incorporated into Japanese quail (starter and finisher) basal diets formulated as shown in Table 1. The experimental diets were prepared and formed for four different treatments as shown in Table 2. Japanese quails of all treatments reared in cage system of management with standard management practices throughout the experimental period. The birds were fed with experimental diet as prescribed up to approximately nine weeks of age (Table 3 ). 


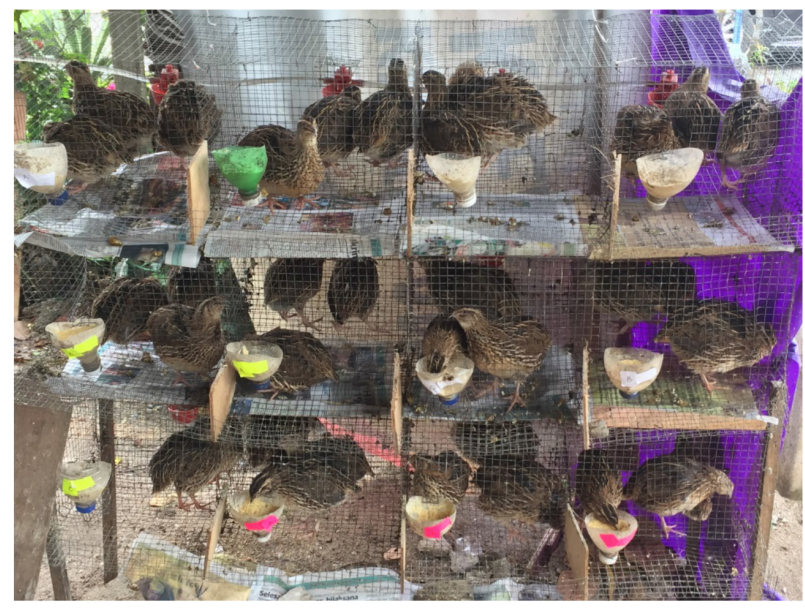

Figure 1: Caging method of Japanese quails

Table 1: Ingredients and chemical composition of the basal diet fed to laying Japanese quails (Sahin et al., 2008)

\begin{tabular}{lc}
\hline \multicolumn{1}{c}{ Ingredient } & Amount, $\frac{\mathrm{g}}{100 \mathrm{~g}}$ \\
\hline Ground corn & 58.62 \\
Soybean meal & 26.72 \\
Vegetable oil & 3.80 \\
Limestone & 8.60 \\
Dicalcium phosphate & 1.60 \\
Vitamin-mineral premix & 0.25 \\
DI-methionine & 0.10 \\
Sodium chloride & 0.35 \\
Metabolizable energy, MJ/kg & 12.4 \\
Crude protein, g/100g & 14.00 \\
Calcium, g/100g & 3.53 \\
Phosphorus, g/100g & 0.65 \\
\hline
\end{tabular}

Table 2: Feed formulation according to treatments

\begin{tabular}{ccc}
\hline Treatments & Commercial Feed per day $(\mathbf{g})$ & Powdered Roselle $(\mathrm{g})$ \\
\hline Control $(0 \%)$ & 20 & 0 \\
Treatment 1 (2\%) & 19.6 & 0.4 \\
Treatment 2 (4\%) & 19.4 & 0.6 \\
Treatment 3 (6\%) & 19.2 & 0.8 \\
\hline
\end{tabular}


Table 3: Schedule for Japanese quails' feeding

\begin{tabular}{cc}
\hline Description & Week \\
\hline Commercial feed & $1-4$ \\
Commercial feed + powdered roselle by-product & $5-9$ \\
Egg analysis & 4 \\
\hline
\end{tabular}

\section{Parameter Evaluation}

\section{Number and Weight of Eggs Produced}

The number of eggs per treatment was counted and recorded manually every three days once the Japanese quails started to lay eggs. Meanwhile, the average weight obtained from each treatment was by using weighing balance.

\section{Colour of Egg Yolk and Albumen}

The colour of both egg yolk and white was taken to determine whether there any significant changes occurred in the colour due to anthocyanin content through the ingestion of roselle by-product.

The Roche Yolk Colour Fan (RYCF) is widely accepted as the standard for measuring yolk colour on reliable basis (Figure 2). Each fan blade contains a colour that has been measured objectively, defined the desired yolk colour (Beardsworth \& Hernandez, 2004). The colour of egg albumen was measured using a HunterLab colorimeter. Colour expressed in Hunter Lab units L* (Lightness/ darkness), a* (redness/ greenness) and $\mathrm{b}^{*}$ (yellowness/blueness).

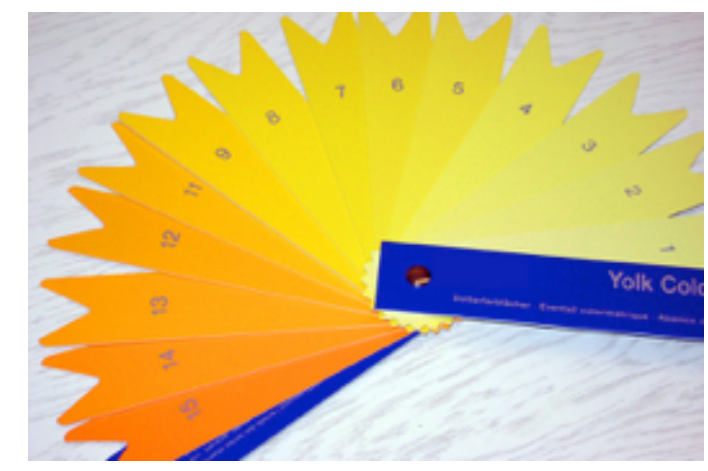

Figure 2: Roche Yolk Colour Fan (RYFC) (Beardsworth \& Hernandez, 2004)

\section{pH Analysis}

The yolk was separated from the albumen. The $\mathrm{pH}$ of the albumen and the yolk was measured with a $\mathrm{pH}$ meter. The sample was then homogenised in $20.0 \mathrm{ml}$ of deionised water in a beaker. The $\mathrm{pH}$ meter was standardised using buffer solution. The yolk and albumen were then mixed thoroughly for each egg sample and the $\mathrm{pH}$ readings were recorded as whole egg (Mathew et al., 2016).

\section{Ascorbic Acid Analysis}

Ascorbic acid determination was carried out by titration method using Indophenol solution. The standardisation is done by titrating standard ascorbic acid till the appearance of permanent pale pink colour as end point. Then, $10 \mathrm{ml}$ of made-up solution of egg mixture with oxalic acid was titrated against the Indophenol dye till the end point. The amount of ascorbic acid present in the samples was recorded. 
Analysis of 2, 2-Diphenyl-2-picrylhydrazyl (DPPH) Assay

The antioxidant activity of the eggs and the standard was assessed on the basis of radical scavenging effect of the stable DPPH free radical activity (Mohd-Esa et al., 2010). A total of $1 \mathrm{ml}$ of $1 \mathrm{mM}$ DPPH in methanol was added to test tubes containing $5 \mathrm{ml}$ of the sample extracts. A control was prepared by adding $4 \mathrm{ml}$ of DPPH solution to $5 \mathrm{ml}$ of $80 \%$ methanol. The samples were kept in the dark for 30 minutes and followed by absorbance readings at 517 nm using UV-visible spectrophotometer (UV1601; Shimadzu Corp., Kyoto, Japan). The percentage of free radical-scavenging activity was calculated based on the following equation (Mohd-Esa et al., 2010):

Percentage of free radical scavenging activity $(\%)=1-\left(\frac{x}{y}\right) \times 100$, where;
$\mathrm{X}$ - absorbance of sample at $517 \mathrm{~nm}$

$\mathrm{y}$ - absorbance of control at $517 \mathrm{~nm}$

\section{Haugh Unit}

Haugh unit (HU) is the measurement for the freshness of eggs. An egg was weighed and broken onto a flat surface. An egg micrometer was used to determine the height of the thick albumen (Figure 3). The height correlated with the weight helps in determining the Haugh unit or HU rating. The higher the number of the Haugh unit, the better the quality of the egg is in the sense of freshness and the egg quality. The HU of samples was measured based on the following formula (Santos et al., 2014):

Haugh units $=100 \times \log \left(\mathrm{H}+7.57-1.7 \times \mathrm{W}^{0.37}\right)$, where;

$\mathrm{H}$ - average thick white height ( $\mathrm{mm})$,

$\mathrm{W}$ - egg weight (g)

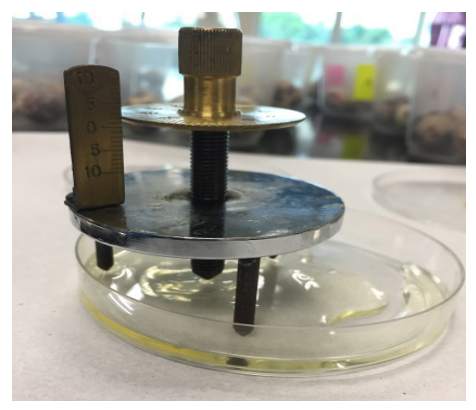

Figure 3: Haugh unit apparatus

\section{Data Analysis}

Data collected were subjected to one-way ANOVA and using the IBM SPSS statistical analysis to determine if there is any significance difference $(p<0.05)$ between each treatment.

\section{Results and Discussion}

\section{Effect of Different Concentration of Roselle by-Product on Egg Production}

There were no significant effects $(p>0.05)$ on egg production and egg weight by the different concentrations of roselle by-product studied (Figures 4 and 5). These results are similar to the finding by Ayasan et al. (2005); Sahin et al.
(2008) and Figueiredo et al. (2012) with similar research studies on egg production with different types of dietary treatments. Besides, egg weight resulting from the dietary treatments did not show any differences $(p>0.05)$ as compared to the control. These results indicate that the concentrations of roselle by-product used are probably below the needs of the quails and the solubility of antioxidant into the eggs to be enriched hardly occurs (Figueiredo et al., 2012) due to complex matrix of egg components (Hatta et al., 2007). Besides, roselle by-products were also not reported with high that contributed to the production of egg (protein) (Abdul Rahim, 2017). 


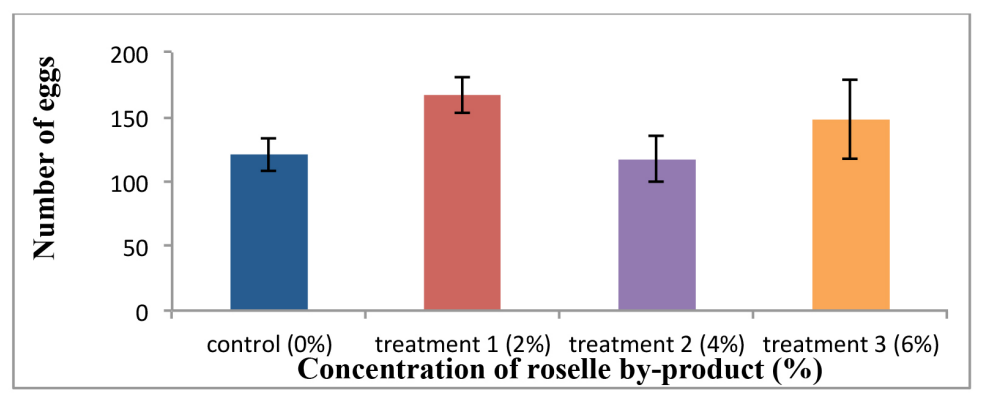

Figure 4: Effect of different concentrations of roselle by-product on number of eggs produced

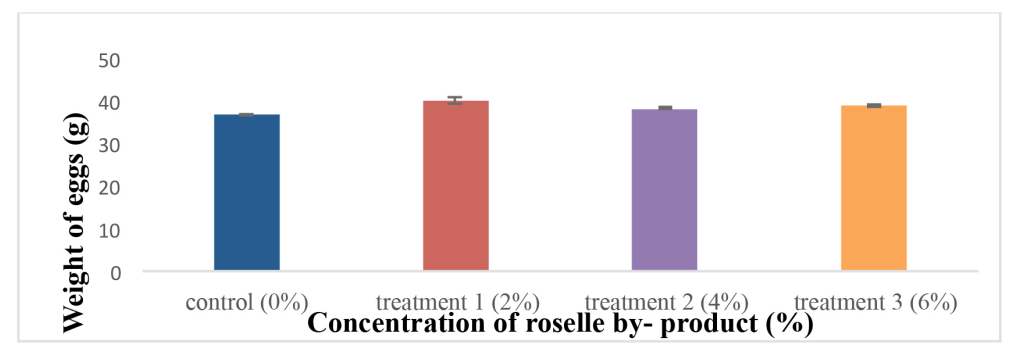

Figure 5: Effect of different concentrations of roselle by-product on weight of egg

Effect of Different Concentration of Roselle by-Product on Egg Yolk Colour

There was no significant difference on yolk colour based on Royal Yolk Fan Colour score where all the treatments had the same average score of nine (Figure 6). Similar result was recorded on the yolk colour in the study of feeding with essential oil (Ding et al., 2017). Though, this result is contrary to the findings by Sahin et al. (2008); Hammershoj et al. (2010) and Djukic-Stojcic et al. (2012) where their yolk colour had significant effect from their dietary treatments. Egg yolk comprises of water, lipids and proteins where yolk lipids exist mainly as lipoproteins (Hatta et al., 2007). Meanwhile, anthocyanin which is the main antioxidant in the roselle by-product (Abdul Rahim, 2017) is water soluble flavonoid compound (Ahmadiani et al., 2014) and hence does not dissolve readily in egg yolk lipid which stands $30 \%$ of yolk weight (Hatta et al., 2007).

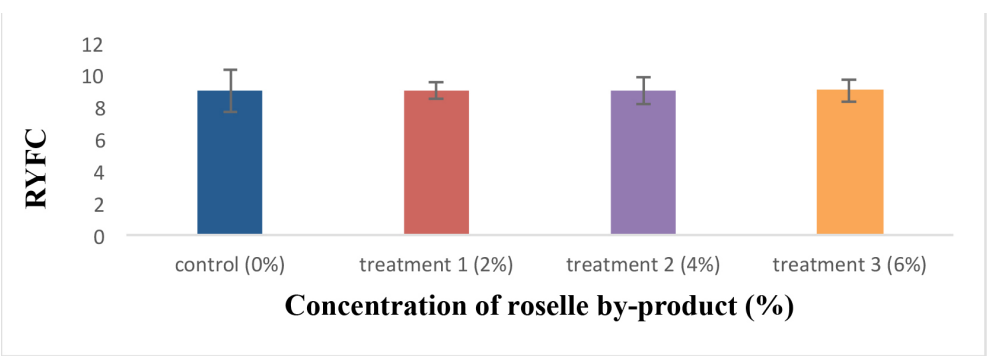

Figure 6: Effect of different concentrations of roselle by-product on RYFC value of eggs 
Effect of Different Concentration of Roselle by-Product on Albumen Colour

Lightness/Darkness $\left(\mathrm{L}^{*}\right)$ of egg albumen was insignificant $(\mathrm{p}>0.05)$ on different concentrations of roselle by-product given in diets. According to the results shown in Figure 7, it can be said that the brightness of albumen remained almost similar with increased concentration of roselle by-product. The slightly highest brightness level can be seen in treatment of $2 \%$ with a mean $(n=3) \pm$ standard deviation stated (37.00 \pm 4.72$)$ (Figure 7). However, there were significant effects $(\mathrm{p}<0.05)$ on the albumen redness $\left(a^{*}\right)$ and yellowness $\left(b^{*}\right)$. Treatment one with $2 \%$ of roselle by-product had positive redness values whereas others showed negative redness values that indicate chromaticity of treatment one shifts towards brighter red colour. Moreover, the significant result of yellowness $\left(b^{*}\right)$ can be seen clearly between treatment one and treatment three with $2 \%$ and $6 \%$ of roselle by-product. Enhancement of albumen redness $\left(a^{*}\right)$ and yellowness $\left(b^{*}\right)$ can be the result of deposition of the anthocyanin pigment from roselle by-product supplemented in the diet. According to Herber-Mcneill and Van Elswyk (1998), dietary pigments have more uptake efficiency as compared to other types of dietary substances as their study had significant effect $(\mathrm{p}<0.05)$ on yolk redness $\left(\mathrm{a}^{*}\right)$ from feeding marine algae. Also, previous work by Haq et al. (1996) confirms that carotenoids such as canthaxanthin are efficiently deposited in egg yolk with significant yellowness $\left(b^{*}\right)$ detected when added to poultry feeding.

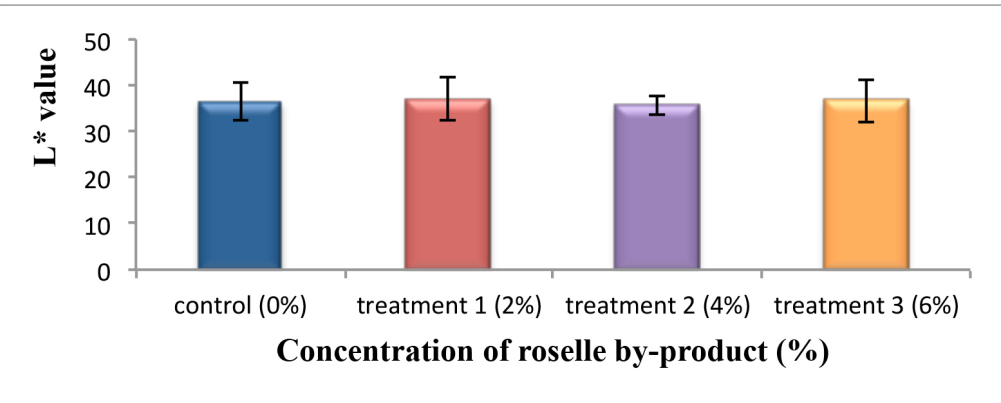

Figure 7: Effect of different concentrations of roselle by-product on lightness ( $\left.\mathrm{L}^{*}\right)$ of egg's albumen

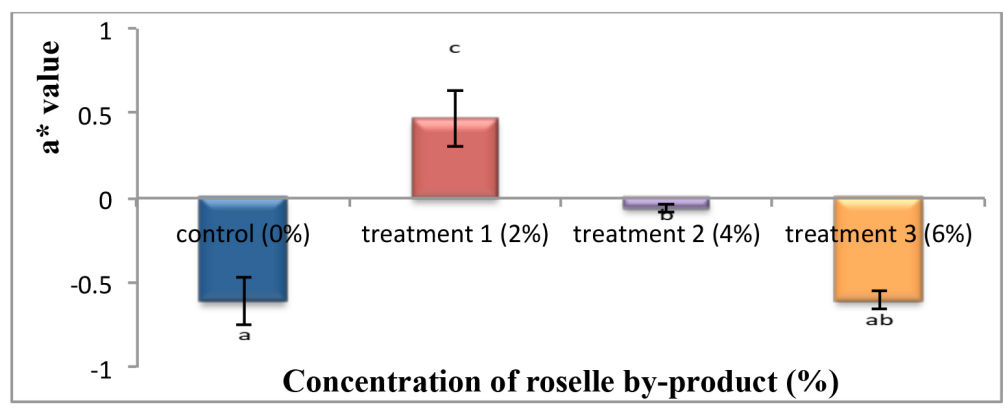

Figure 8: Effect of different concentrations of roselle by-product on redness ( $\left.\mathrm{a}^{*}\right)$ of egg's albumen 


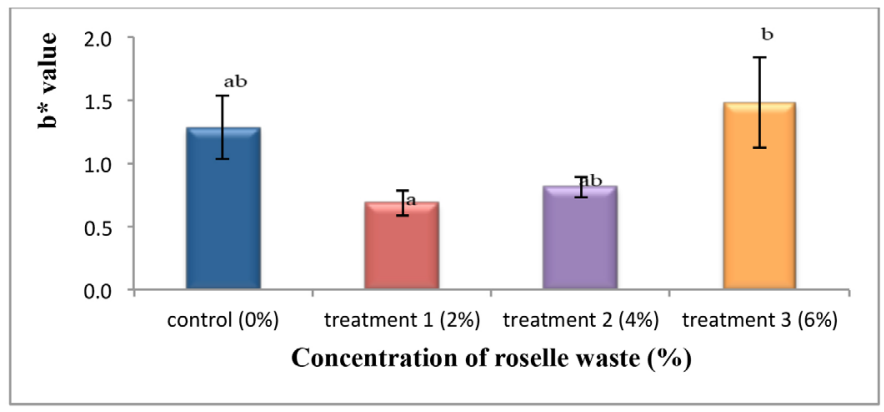

Figure 9: Effect of different concentrations of roselle by-product on yellowness ( $\left.b^{*}\right)$ of egg's albumen

Effect of Different Concentration of Roselle by-Product on $\mathrm{pH}$

The data shown in Figures 10, 11 and 12 demonstrated that $\mathrm{pH}$ of egg yolk, albumen and whole egg from the treatments were found to be almost similar as control. But, dietary treatments had significant influence on the $\mathrm{pH}(\mathrm{p}<0.05)$. Albumen $\mathrm{pH}$ showed vast difference between control and the treatments especially treatment one $(2 \%)$ and treatment three (4\%) with mean $(n=3) \pm$ standard deviation stated $9.36 \pm 0.07$ and $9.09 \pm 0.04$ respectively as compared to the control $8.97 \pm 0.02$. Whole egg $\mathrm{pH}$ of had significant effect $(p<0.05)$ where the treatment three with $6 \%$ of roselle by-product had highest mean $(n=3) \pm$ standard deviation of $(7.84 \pm 0.01)$.

Silversides and Scott (2001) stated that in a normal laid egg's yolk $\mathrm{pH}$, albumen $\mathrm{pH}$ and whole egg $\mathrm{pH}$ is generally lie between $6.4-6.9,7.6$ 8.5 and 6.5-6.7 respectively. $\mathrm{pH}$ measurements for both yolk and whole egg in this study are almost in the range of normal eggs despite of supplementation of different concentration of roselle by-product with $\mathrm{pH}$ of 4.23 . However, the albumen $\mathrm{pH}$ had shown slightly higher $\mathrm{pH}$ readings from the normal range which may be due to loss of carbon dioxide through the shell pores (Fallis, 2013). Besides, it depends on the equilibrium between dissolved carbon dioxide, carbonate ions and protein which can be easily affected by external environment (Fallis, 2013). In overall performance, acidic nature of roselle by-product did not affect the neutral nature of the eggs from the dietary treatments despite of the significant results.

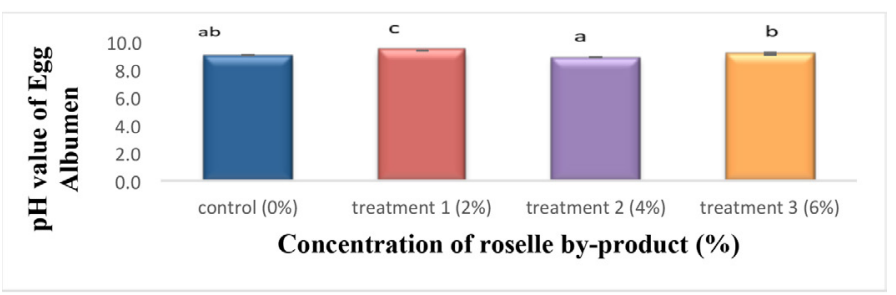

Figure 10: Effect of different concentrations of roselle by-product on $\mathrm{pH}$ reading of egg albumen. Each letter showed significant difference between the groups in homogeneous subsets 


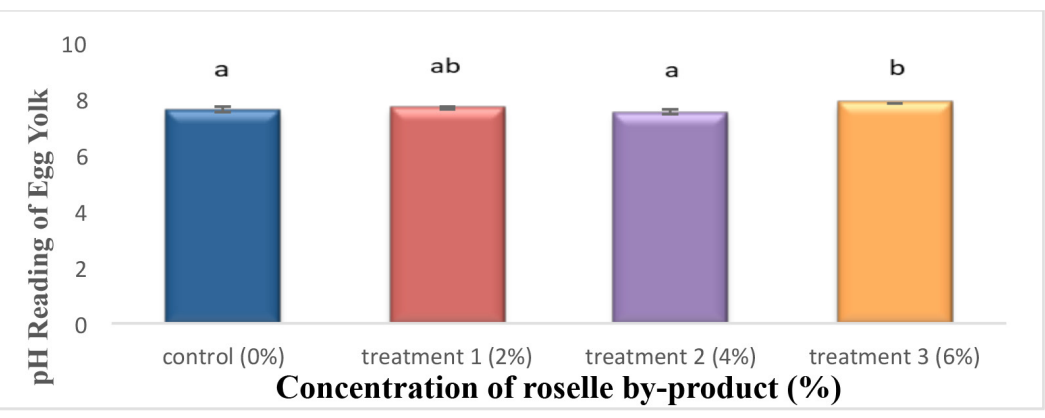

Figure 11: Effect of different concentrations of roselle by-product on $\mathrm{pH}$ reading of egg yolk. Each letter showed significant difference between the groups in homogeneous subsets

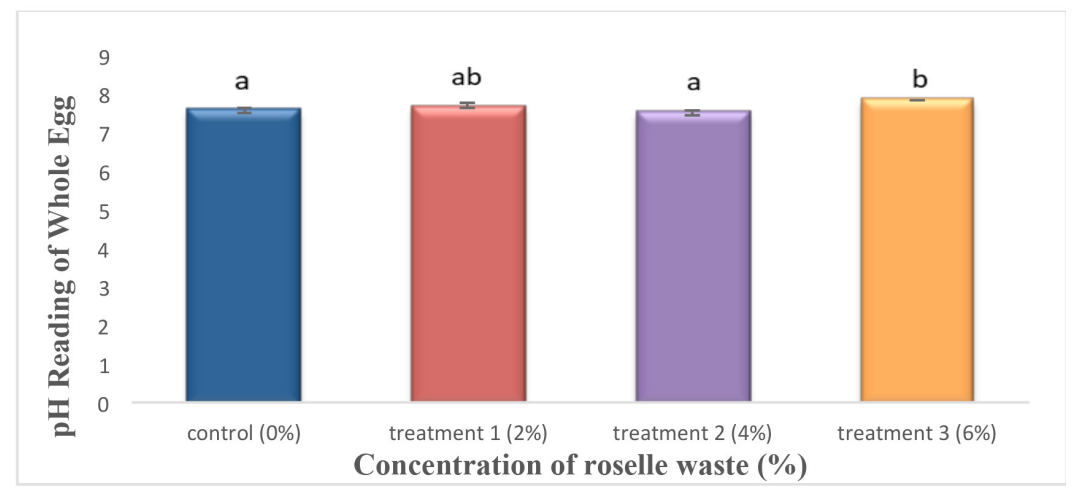

Figure 12: Effect of different concentration of roselle by-product on $\mathrm{pH}$ reading of whole egg. Each letter showed significant difference between the groups in homogeneous subsets

Effect of Different Concentration of Roselle by-Product on Egg Haugh Unit

A response was observed from the significant study $(\mathrm{p}<0.05)$ on Haugh unit from these dietary treatments, though, treatment one with $2 \%$ of roselle by-product had marked the highest mean $(n=3) \pm$ standard deviation of $80.02 \pm 0.82$ (Figure 13). The United States Department of Agriculture categorised the egg qualities according to Haugh unit where AA (100 to 72), A (71 to 60), B (59 to 30) and C (below 29) (Santos et al., 2014). In this case, all the experimental eggs can be classified into AA quality. The results of this study are in agreement with the findings of Sahin et al. (2008) and Wang et al. (2015) who observed significant effects $(\mathrm{p}<0.05)$ from their dietary treatment of protein sources and lycopene respectively. On the other hand, Santos et al. (2014) who reported that there is no influence on digestible lysine levels for laying hens on Haugh unit. Albumen is a major water reservoir of the egg (Hatta et al., 2007) which also makes it an equal contributor of proteins. Since anthocyanin pigment in roselle by-product is categorised into water soluble flavonoid (Kong et al., 2003; Abou-Arab et al., 2011) and hence the significant effect shown is most likely due to the incorporation of anthocyanin pigment into the egg albumen. Generally, Haugh unit acts as freshness indicator for safety consumption where it can be used to detect the interior quality deterioration of an egg (Wang et al., 2015). 


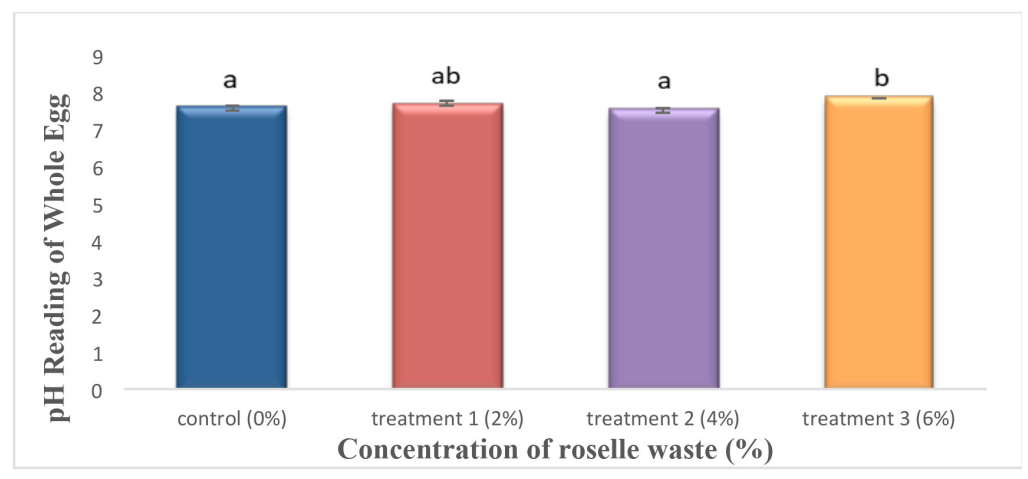

Figure 13: Effect of different concentrations of roselle by-product on Haugh unit of eggs. Each letter showed significant difference between the groups in homogeneous subsets

Effect of Different Concentration of Roselle byProduct on Egg Ascorbic Acid

There was significant influence $(\mathrm{p}<0.05)$ of the levels of dietary treatments on ascorbic acid content. Though, it can be seen in Figure 14 that the volume of DCPIP used was decreasing gradually with increasing concentration of roselle by-product. DCPIP reagent was used as an indicator (Mohamed et al., 2007) to analyse the amount of ascorbic acid content in egg samples. The higher the volume of DCPIP used, the higher the amount of ascorbic acid content in the samples. From the results obtained, it can be said that the ascorbic acid content in eggs had influence from the dietary treatment of roselle by-product. It was an expected result as the roselle by-product analysis showed lower ascorbic content with the average value of 0.77 . This result is contrary to the findings of
Wong et al., 2002; Abou-Arab et al., 2011 who observed that roselle by-product has a higher content of ascorbic acid and had an opinion where it can be utilised for various application in the food industry. Generally, ascorbic acid is a water soluble vitamin that has been shown to be effective against the superoxide radical anion, $\mathrm{H}_{2} \mathrm{O}_{2}$, the hydroxyl radical and singlet oxygen (Nimalaratne \& Wu, 2015). Thus, it is always related to antioxidant properties that contributed for extending shelf life of a food (Patras et al., 2009). However, ascorbic acid has less contribution to the eggs as both albumen and yolk are entirely lacking or free from vitamin C in general (Hatta et al., 2007); Sahin et al. (2008); Nimalaratne \& Wu; (2015) \& Zaheer (2017) stated in their papers that eggs required lipidsoluble vitamins in order to prevent propagation of lipid peroxidation reactions. 


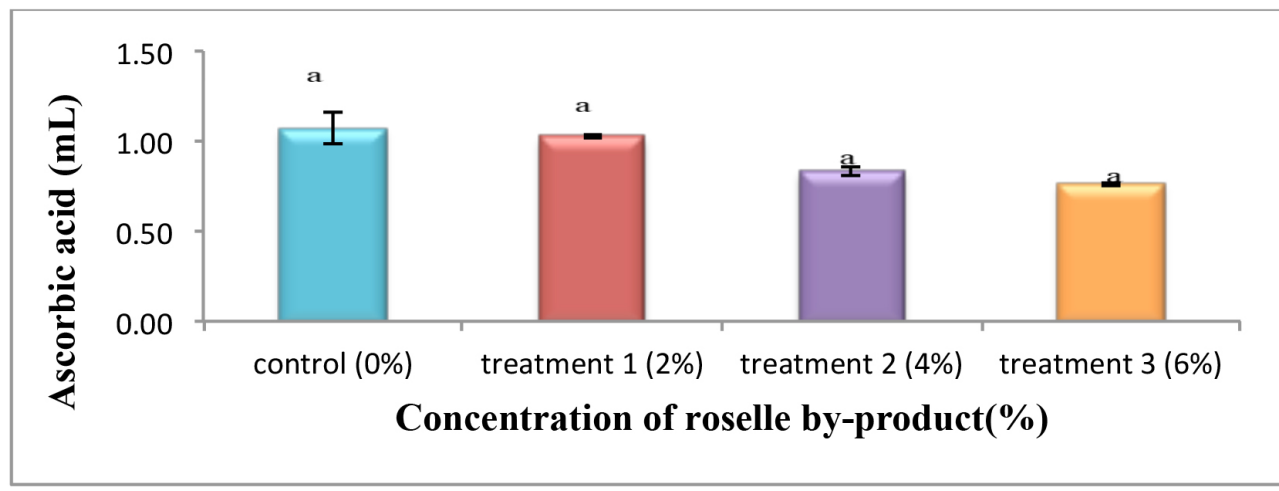

Figure 14: Effect of different concentrations of roselle by-product on ascorbic acid of eggs. Each letter showed the slightest significant difference between the groups in homogeneous subsets

Effect of Different Concentration of Roselle by-Product on 2, 2-Diphenyl-2-picrylhydrazyl (DPPH) Assay

There was no significant difference $(\mathrm{p}>0.05)$ found on percentage of DPPH inhibition of eggs from the roselle by-product supplementation in diets. The antioxidant roselle by-products did not contribute to the antioxidant properties in the egg. Although a study from Abdul Rahim
(2017) found a significant amount of antioxidant in roselle by-product, but the concentration used in this study did not seem enough. Amino acids such as cystein, methionine, tyrosine, tryptophan, phenylalanine and histidine in peptides from egg white and egg yolk are the main contributors to the antioxidant activities in egg (Gładkowski et al., 2014; Nimalaratne \& $\mathrm{Wu}, 2015)$.



Figure 15: Effect of different concentrations of roselle by-product on percentage of DPPH inhibition of eggs

Overall, the incorporation of rosellebyproduct in bird feed showed the potential to produce better quality eggs. Although roselle by-product was reported with abundance of antioxidant (Abdul Rahim, 2017) due to the lower concentration, the effect of the properties is not sufficient to affect most of the postharvest quality of the eggs. The concentration of the feed needs to be increased and reformulated with basal diets to meet the requirements needed by the animal. The analysis of the animal feed too needs to be done as the additional parameters to see the correlation of the nutrients in the feed and the postharvest quality of eggs. 


\section{Conclusion}

This study showed that the addition of roselle by-products into commercial feed affected the weight of eggs, a* $b^{*}$ value, ascorbic acid and Haugh unit of Japanese quail egg unit where the $2 \%$ concentration addition of roselle showed better value. The incorporation of roselle by-products in animal feed has the potential to produce egg of better quality. If this approach is realized, it would be possible to fulfil the demands of the consumers for natural antioxidant-enriched healthy eggs. Moreover, full utilization of roselle that includes its byproduct could lead the industry to a lower-waste agribusiness as well as increasing industrial profitability through environmentally friendly operating processes.

\section{Acknowledgements}

The authors gratefully acknowledged the Faculty of Fisheries and Food Science for supporting this research with facilities and financial support.

\section{References}

Abdul Rahim, E. (2017). Physicochemical and antioxidant properties of different by-products of roselle (Hibiscus sabdariffa) beverages (Undergraduate Thesis), Universiti Malaysia Terengganu, Terengganu).

Abou-Arab, A. a, Abu-Salem, F. M., \& AbouArab, E. A. (2011). Physico-chemical properties of natural pigments (anthocyanin) extracted from Roselle calyces (Hibiscus subdariffa). Journal of American Science, 7(7), 445-456.

Ahmadiani, N., Robbins, R. J., Collins, T. M., \& Giusti, M. M. (2014). Anthocyanins contents, profiles, and color characteristics of red cabbage extracts from different cultivars and maturity stages. Journal of Agricultural and Food Chemistry, 62(30), 7524-7531.

Ayala-Zavala, J. F., Rosas-Domínguez, C., Vega-Vega, V., \& González-Aguilar, G.
A. (2010). Antioxidant enrichment and antimicrobial protection of fresh-cut fruits using their own byproducts: Looking for integral exploitation. Journal of Food Science, 75(8).

Baiano, A. (2014). Recovery of biomolecules from food wastes - A review. Molecules, 19(9), 14821-14842.

Beardsworth, P., \& Hernandez, J. (2004). Yolk colour-an important egg quality attribute. Int Poult Prod, 12(5), 17-18. Retrieved from http://www.positiveaction.info/pdfs/ articles/pp12.5p17.pdf

Botelho, G. G., Falbo, M. K., Ost, P. R., Czekoski, Z. M., Raviolo, A. E., Giotto, F. M., \& Morais, R. N. (2015). Physiological performance of quails that underwent dietary and pharmacological manipulation of cholesterol. Journal of Animal Physiology and Animal Nutrition, 99(3), 424-429.

Descalzo, A. M., \& Sancho, A. M. (2008). A review of natural antioxidants and their effects on oxidative status, odor and quality of fresh beef produced in Argentina. Meat Science, 79(3), 423-436.

Djukic-Stojcic, M., Milosevic, N., Peric, L., Jajic, I., \& Tolimir, N. (2012). Egg quality of Japanese quail in Serbia (Coturnix coturnix japonica). Biotechnology in Animal Husbandry, 28(3), 425-431.

Fallis, A. (2013). Culture and Anarchy: An Essay in Political and Social Criticism. Journal of Chemical Information and Modeling (Vol. 53).

Figueiredo, G., Bertechini, A., Fassani, E., Rodrigues, P. B., Brito, J. Á., \& Castro, S. (2012). Performance and egg quality of laying hens fed with dietary levels of digestible lysine and threonine. Arquivo Brasileiro de Medicina Veterinária $E$ Zootecnia, 64(3), 743-750.

Gładkowski, W., Kiełbowicz, G., Chojnacka, A., Bobak, łukasz, Spychaj, R., Dobrzański, Z., Wawrzeńczyk, C. (2014). The effect of feed supplementation with dietary 
sources of n-3 polyunsaturated fatty acids, flaxseed and algae Schizochytrium sp., on their incorporation into lipid fractions of Japanese quail eggs. International Journal of Food Science and Technology, 49(8), $1876-1885$.

Hatta, H., Kapoor, M. P., \& Juneja, L. R. (2007). Bioactive components in egg yolk. Egg Bioscience and Biotechnology.

Haq, A. U., Bailey, C. A. \& Chinnah, A. (1996). Effect of $\beta$-carotene, canthaxanthin, lutein, and vitamin $\mathrm{E}$ on neonate immunity of chicks when supplemented in the broiler breeder diets. Poultry Science, 75:10921097.

Herber-Mcneill, S. M., \& Van Elswyk, M. E. (1998). Dietary Marine Algae Maintains Egg Consumer Acceptability while Enhancing Yolk Color. Poultry Science, 77(3), 493-496.

Hammershøj, M., Kidmose, U., \& Steenfeldt, S. (2010). Deposition of carotenoids in egg yolk by short-term supplement of coloured carrot (Daucus carota) varieties as forage material for egg-laying hens. Journal of the Science of Food and Agriculture, 90(7), 1163-1171.

Kong, J. M., Chia, L. S., Goh, N. K., Chia, T. F., \& Brouillard, R. (2003). Analysis and biological activities of anthocyanins. Phytochemistry, 64(5), 923-933.

Mathew, A., Olufemi, A., Foluke, A., \& Abel, O. (2016). Relationship of temperature and length of storage on ph of internal contents of chicken table egg in humid tropics. Biotechnology in Animal Husbandry, 32(3), 285-296.

Mine, Y. (1995). Recent advances in the understanding of egg white protein functionality. Trends in Food Science and Technology, 6(7), 225-232.

Mohd-Esa, N., Hern, F. S., Ismail, A., \& Yee, C. L. (2010). Antioxidant activity in different parts of roselle (Hibiscus sabdariffa L.) extracts and potential exploitation of the seeds. Food Chemistry, 122(4), 1055-1060.
Mohamed, R., Fernández, J., Pineda, M., \& Aguilar, M. (2007). Roselle (Hibiscus sabdariffa) seed oil is a rich source of $\gamma$-tocopherol. Journal of Food Science, $72(3)$

Nimalaratne, C., \& Wu, J. (2015). Hen egg as an antioxidant food commodity: A review. Nutrients, 7(10), 8274-8293.

Sahin, N., Akdemir, F., Orhan, C., Kucuk, O., Hayirli, A., \& Sahin, K. (2008). Lycopeneenriched quail egg as functional food for humans. Food Research International, 41(3), 295-300.

Santos, T. A. dos, Geraldo, A., Machado, L. C., Pelícia, K., Simão, S. D., \& Vieira Filho, J. A. (2014). Digestible lysine levels for laying hens and their effects on egg quality. Acta Scientiarum. Animal Sciences, 36(1), 41.

Silversides, F. G., \& Scott, T. A. (2001). Effect of storage and layer age on quality of eggs from two lines of hens. Poultry Science, 80(8), 1240-1245.

Varzakas, T., Zakynthinos, G., \& Verpoort, F. (2016). Plant Food Residues as a Source of Nutraceuticals and Functional Foods. Foods, 5(4), 88.

Wang, X., Wu, S., Zhang, H., Yue, H., Qi, G., \& Li, J. (2015). Effect of dietary protein sources and storage temperatures on egg internal quality of stored shell eggs. Animal Nutrition, 1(4), 299-304.

Wenk, C. (2003). Herbs and botanicals as feed additives in monogastric animals. AsianAustralasian Journal of Animal Sciences, 16(2), 282-289.

Wong, P., Yusof, S., Ghazali, H. M., \& Che Man, Y. B. (2002). Physico-chemical characteristics of roselle (Hibiscus sabdariffa L.). Nutrition \& Food Science, 32(2), 68-73.

Zaheer, K. (2017). Hen egg carotenoids (lutein and zeaxanthin) and nutritional impacts on human health: a review. CyTA - Journal of Food, 15(3), 474-487. 
